\title{
The Problem of Unconceived Objections
}

Forthcoming in Argumentation

Moti Mizrahi

St. John's University

motimizra@gmail.com

\begin{abstract}
In this paper, I argue that, just as the Problem of Unconceived Alternatives (PUA) provides a basis for a New Induction on the History of Science to the effect that a realist view of science is unwarranted, the Problem of Unconceived Objections (PUO) provides a basis for a New Induction on the History of Philosophy to the effect that a realist view of philosophy is unwarranted. I raise this problem not only for skepticism's sake but also for the sake of making a point about philosophical argumentation, namely, that anticipating objections to one's claim is not the same as supporting one's claim. In other words, defending $p$ from objections does not amount to support or evidence for $p$. This, in turn, presents dialectical and pragma-dialectical approaches to argumentation with the following question: does proper argumentation require that arguers anticipate and respond to unconceived objections?
\end{abstract}

Keywords: anti-realism; argument; argumentation; dialectics; pragma-dialectics; problem of unconceived alternatives; problem of unconceived objections

\section{Introduction}

For the most part, philosophers tend to assume that defending a claim amounts to support or evidence for that claim. For example, in a seminal paper published in The Journal of Philosophy (vol. 83), Alston (1986, p. 655) claims that "the perception of God plays an epistemic role with respect to beliefs about God." Alston (1986, p. 656) proceeds mainly "by way of responding to a number of objections." Presumably, Alston assumes that defending his claim about the epistemic role of God perceptions against objections amounts to support or evidence for that claim. I think that this is mistaken. Defending a claim is not the same as supporting a claim. No matter how many objections to one's claim one anticipates, responding to objections does not amount to support or evidence for one's claim. Why? Because of the Problem of Unconceived Objections (PUO) and the New Induction on the History of Philosophy. In the next section, then, I articulate the Problem of Unconceived Objections (PUO) and sketch a New Induction on the History of Philosophy, which is parallel to an argument against scientific realism known as the New Induction. 


\section{The Problem of Unconceived Objections (PUO)}

The Problem of Unconceived Objections (PUO) draws its inspiration from the Problem of Unconceived Alternatives (PUA). In Exceeding Our Grasp, Stanford (2006, p. 20) argues that "the history of scientific inquiry itself offers a straightforward rationale for thinking that there typically are alternatives to our best theories equally well confirmed by the evidence, even when we are unable to conceive of them at the time." Stanford calls this the Problem of Unconceived Alternatives (PUA). The PUA, Stanford argues, provides a basis for a New Induction on History of Science. ${ }^{1}$ This inductive argument can be summed up as follows (Magnus 2010, p. 807):

\section{A New Induction on the History of Science}

(NIS1) The historical record reveals that past scientists typically failed to conceive of alternatives to their favorite, then-successful theories.

Therefore:

(NIS2) (Probably) Present scientists fail to conceive of alternatives to their favorite, nowsuccessful theories.

Therefore:

(NIS3) (Probably) We should not believe our present scientific theories.

Stanford's New Induction on the History of Science purports to show that a realist view of science, according to which "mature and predictively successful scientific theories are wellconfirmed and approximately true" (Psillos 2006, p. 135), is unwarranted.

Now, consider the following problem, which is simply the PUA applied to philosophy instead of science. In much the same way that "the history of scientific inquiry itself offers a straightforward rationale for thinking that there typically are alternatives to our best theories equally well confirmed by the evidence, even when we are unable to conceive of them at the time" (Stanford 2006, p. 20), the history of philosophical inquiry offers a straightforward rationale for thinking that there typically are serious objections to our best philosophical theories, even when we are unable to conceive of them at the time. In other words, the historical record shows that philosophers have typically failed to conceive of serious objections to their well-defended philosophical theories. As the historical record also shows, however, other philosophers subsequently conceived of serious objections to those well-defended philosophical theories. For example:

- In The First Treatise of Government (1689/1988), John Locke raises serious objections (to the point of refutation, some might say) to Sir Robert Filmer's (1680/1991) doctrine of the Divine Right of Kings.

- In his seminal paper "On Denoting" (1905), and later in his Introduction to Mathematical Philosophy (1919), Russell articulates and defends his description theory of proper

\footnotetext{
${ }^{1}$ Stanford calls this argument "New Induction" to distinguish it from the pessimistic induction due to Laudan (1981). For more on the pessimistic induction, see Mizrahi (2012b).
} 
names. The theory now faces what are considered by many philosophers to be serious objections, which were put forth by Kripke (1980) among others.

- In the first edition of Language, Truth, and Logic (1936), and in the second edition (1946), Ayer articulates and defends the verification principle as a criterion of meaning. Serious objections to the verification principle were subsequently put forth by Church (1949).

- Logical positivism enjoyed a relatively long period of success until Kuhn (1962, p. 1) decided it was time for "a decisive transformation in the image of science by which [they were then] possessed."

- In Conjectures and Refutations (1963), Popper articulates and defends the notion of verisimilitude. This notion was subsequently met with serious objections from Miller (1974), Tichý (1974), and Grünbaum (1976).

- Legend has it that the Justified True Belief (JTB) analysis of knowledge was taken as a given by most philosophers until Gettier (1963) came along and articulated a serious objection to JTB (see Shope 1983 and Pollock 1986; cf. Turri 2011).

- Contractarianism, whose most prominent recent defender is Gauthier (1986), now faces what many consider to be a serious problem known as the outlier problem (Silvers and Francis 2005).

- Modal fictionalism, as articulated by Rosen (1990), now faces what many consider to be serious objections, such as the Brock/Rosen objection (Brock 1993) and the Hale dilemma (1995).

I could cite a lot more examples from the historical record of philosophy, but I think these are enough to illustrate the PUO.

Now, just as Stanford's PUA provides a basis for a New Induction on the History of Science, the PUO provides a basis for a New Induction on the History of Philosophy, since the PUO is just the PUA applied to philosophy rather than to science. The New Induction on the History of Philosophy and the New Induction on the History of Science have a parallel logical structure:

A New Induction on the History of Philosophy

(NIP1) The historical record reveals that past philosophers typically failed to conceive of serious objections to their favorite, then-defensible theories.

Therefore:

(NIP2) (Probably) Present philosophers fail to conceive of serious objections to their favorite, now-defensible theories.

Therefore:

(NIP3) (Probably) We should not believe our present philosophical theories.

Stanford's New Induction on the History of Science and the New Induction on the History of Philosophy begin with a historical basis of a pattern of failures: failure to conceive of alternatives in the case of Stanford's New Induction on the History of Science and failure to conceive of serious objections in the case of the New Induction on the History of Philosophy. Then, by 
inductive inference, we move from past cases to present cases and subsequently draw an antirealist conclusion. ${ }^{2}$

It is important to note that, as in the case of the New Induction on the History of Science, where (NIS3) follows inductively from (NIS2) because, for any given scientific theory, that theory is more likely to be a theory to which there is an alternative theory that remains hitherto unconceived, in the case of the New Induction on the History of Philosophy, (NIP3) follows inductively from (NIP2) because, for any given philosophical theory, that theory is more likely to be a theory to which there are serious objections that remain hitherto unconceived. In other words, if any given philosophical theory is more likely than not to be a theory that has serious objections, even if those objections have not been conceived of yet, and we should not believe theories that have serious objections, then it follows that we should probably not believe any given philosophical theory, since that theory probably has serious objections, even if those objections have not been conceived of yet. To put it yet another way, suppose one is considering whether or not one should believe a philosophical theory PT. Given the PUO and the New Induction on the History of Philosophy, the reasonable response in this case is "Probably not." That is, one should probably not believe that $P T$ is true, since $P T$ probably has serious objections, even if those objections have not been conceived by anyone yet. ${ }^{3}$

It is also important to note that the analogy between Stanford's PUA and the PUO is supposed to be the following:

\section{Alternative theories : scientific theories :: serious objections : philosophical theories}

On almost any model of scientific reasoning, having an equally well-confirmed, alternative theory $T_{2}$ to phenomenon $P$ amounts to a serious objection to theory $T_{1}$. For example, on a simple hypothetico-deductive model (see, e.g., Dogan 2005), observational consequence or test implication, $I$, which is borne out by observation and/or experimentation, confirms $H_{1}$ just in case there is no alternative hypothesis $H_{2}$ that is also confirmed by $I$. If $I$ "confirms" both $H_{1}$ and $H_{2}$ equally well, then it follows that $I$ actually confirms neither, since there is no reason to prefer $H_{1}$ over $H_{2}$. In other words, if one were to put forth the following confirmation argument for $H_{1}$

\footnotetext{
${ }^{2}$ The sort of anti-realism I have in mind here is parallel to the sort of anti-realism that is opposed to scientific realism along the epistemological dimension (Psillos 2006, p. 135); that is, "the epistemological commitment to regard theories as constituting knowledge of both observables and unobservables" (Chakravartty 2013). In that respect, this sort of anti-realism amounts to agnosticism about theoretical knowledge (van Fraassen 1998, p. 213). See also Mizrahi (2012a).

${ }^{3}$ I take it that a serious objection to a philosophical theory is ground for suspending belief about that theory in much the same way that an alternative and equally confirmed theory $T_{2}$ is ground for suspending belief about competing theory $T_{1}$. A rough-and-ready argument for this claim goes like this: We should not believe theories that are unlikely to be true or approximately true. Theories that have serious objections are unlikely to be true or approximately true. Therefore, we should not believe theories that have serious objections. As a perceptive referee pointed out, one could argue that not all serious objections are equal, and hence warrant suspension of belief, in much the same way that not all alternative theories are equal, and hence warrant suspension of belief. For example, among theories $T_{1}$, $T_{2}, T_{3}$, which explain phenomenon $P$ equally well, $T_{2}$ might be more worthy of belief than $T_{3}$, say, because it is simpler, more parsimonious, more elegant, more comprehensive, etc. Typically, however, scientific antirealists tend to think that these theoretical virtues are not truth-conductive. Constructive empiricists, in particular, distinguish between epistemic and pragmatic virtues (van Fraassen 1980, p. 87).
} 
1. If $H_{1}$ (plus auxiliary hypotheses $A_{1} \ldots A_{\mathrm{n}}$ ), then $I$.

2. (As observation and/or experimentation shows) $I$ is the case.

Therefore:

3. (Probably) $H_{1}$.

then this confirmation argument would fail to confirm $H_{1}$, since a similar confirmation argument can be made for $H_{2}$ (since, by stipulation, $I$ confirms $H_{2}$ as well):

1. If $H_{2}$ (plus auxiliary hypotheses $A_{1} \ldots A_{\mathrm{n}}$ ), then $I$.

2. (As observation and/or experimentation shows) $I$ is the case.

Therefore:

3. (Probably) $H_{2}$.

In this case, $I$ does not provide a reason to prefer $H_{1}$ over $H_{2}$, which is why alternative hypothesis $\mathrm{H}_{2}$ amounts to a serious objection to $H_{1}{ }^{4}$

Similarly, on an Inference to the Best Explanation (IBE) model, having an alternative explanation $E_{2}$ for phenomenon $P$ amounts to a serious objection to explanation $E_{1}$. For, in that case, key premises in the inference to the best explanation would be false (see, e.g., Psillos 2002, p. 614 and Iranzo 2007, p. 341):

1. Phenomenon $P$.

2. $E_{1}$ explains $P$.

3. No other hypothesis explains $P$ as well as $E_{1}$ does.

Therefore:

4. (Probably) $E_{1}$.

If $E_{2}$ explains $P$ as well as $E_{1}$ does, then premise (3) in the inference to the best explanation is false. That is why having an alternative explanation $E_{2}$ for $P$ amounts to a serious objection against $E_{1}$.

To sum up, then, alternative theories (whether conceived or unconceived) amount to serious objections to scientific theories, since they show that a confirmation argument or an inference to the best explanation is flawed, and hence are analogous to serious objections to philosophical theories. ${ }^{5}$

\footnotetext{
${ }^{4}$ On differential confirmation, see Erwin and Siegel (1989). See also Achinstein (2001, chap. 12).

${ }^{5}$ Some might think that there is an important difference between alternative, equally confirmed scientific theories and serious objections to philosophical theories, namely, the explanatory function of the former as opposed to the latter. Recall, however, that antirealists do not think that explanatory virtues carry any epistemic weight (see
} 
If this is correct, then the PUO provides a basis for a New Induction on the History of Philosophy in much the same way that the PUA provides a basis for a New Induction on the History of Science. Likewise, the New Induction on the History of Philosophy is an argument for anti-realism about philosophy in much the same way that the New Induction about the History of Science is an argument for anti-realism about science. Although the PUO is analogous to the PUA and the New Induction on the History of Philosophy is parallel to the New Induction on the History of Science, they can be advanced as arguments for philosophical anti-realism and scientific anti-realism, respectively, independently of each other. This is so because each inductive argument draws its support from a distinct historical record; the New Induction on the History of Science draws its support from the historical record of science, whereas the New Induction on the History of Philosophy draws its support from the historical record of philosophy (see the aforementioned examples on pp. 2-3).

\section{Defense $\neq$ Support}

I raise the PUO and the New Induction on Philosophy not only for skepticism's sake but also for the sake of making a point about philosophical argumentation. The point is that anticipating objections to one's claim is not the same as supporting one's claim. In other words, defending a claim against objections does not amount to support or evidence for that claim. To see why, consider Alston's (1986) "Perceiving God" again. Alston (1986, p. 655) defends his claim that "the perception of God plays an epistemic role with respect to beliefs about God" by anticipating and responding to no less than seven objections. Although impressive, his defense does not amount to support or evidence for his claim because of the PUO and the New Induction on the History of Philosophy. By way of illustration, here are two objections Alston (and others who have read his paper, such as editors, reviewers, etc.) failed to anticipate:

- The same "God perceptions" or religious experiences that Alston claims generate $M$ beliefs ( $M$ for manifestation) seem to also "generate in some people the belief that God does not exist, that whatever supernatural powers there may be are either uninterested in us or perhaps positively malevolent" (Baergen 1995, p. 216). For example, many Jews had such experiences after the Holocaust. Although many people have conflicting sense experiences, disagreements seem to be more widespread as far as religious experiences are concerned (Baergen 1995, p. 217).

- Alston claims that we learn through religious experience "that $M$-beliefs can be relied upon only when the subject meets certain moral standards" (Baergen 1995, p. 217). That is, "if your behavior has not been up to a particular moral standard, then your religious experience is not likely to be accurate" (Baergen 1995, p. 217). But what are the moral conditions for accurate religious experiences? "Are we to abstain from 'impure thoughts', or cook our food in certain ways, or perform certain religious ceremonies, or travel to a holy site [...]?” (Baergen 1995, p. 217).

footnote 3 above). In fact, constructive empiricists are critical of Inference to the Best Explanation. See, e.g., van Fraassen (1980, p. 143) and Muller (2008). 
To be clear, I am not saying that one should not anticipate objections to one's claim. Rather, I am saying that defending a claim does not amount to support for that claim because of the PUO and the New Induction on the History of Philosophy.

If this is correct, then the following do not amount to support or evidence for $p$ :

1. Objection 1 is not a serious objection to $p$.

2. Objection 2 is not a serious objection to $p$.

3. Objection 3 is not a serious objection to $p \ldots$

4. Objection $n$ is not a serious objection to $p$.

(1)-(4) do not amount to support or evidence for $p$ because there is probably a serious objection $n$ +1 that one has failed to conceive of, as the PUO shows. If this is correct, then responding to objections is not a proper substitute for good, old-fashion reasons and/or evidence for $p$. By an epistemic reason or evidence for $p$, I mean a proposition $q$ such that, if $q$ is true, then $p$ is either definitely true or probably true. If, given $q, p$ is definitely true, then $q$ provides conclusive support for $p$ (as in deductive arguments). For example: "If this geometrical shape is a square, then this geometrical shape has four equal sides." In this case, the premise $q$ (= "this geometrical shape is a square') provides conclusive support for the conclusion $p$ (= 'this geometrical shape has four equal sides'). In other words, an argument with $q$ (= 'this geometrical shape is a square') as the premise and $p$ (= 'this geometrical shape has four equal sides') as the conclusion counts as a valid deductive argument.

On the other hand, if, given $q, p$ is more likely to be true, then $q$ provides defeasible support for $p$ (as in inductive arguments). For example: "If you smoke cigarettes, then you increase your chances of having a heart attack." In this case, $q$ (= 'you smoke cigarettes') provides defeasible support for $p$ (= 'you increase your chances of having a heart attack'). In other words, an argument with $q$ (= 'you smoke cigarettes') as the premise and $p$ (= 'you increase your chances of having a heart attack') as the conclusion counts as an inductive argument. Now, the PUO shows that premises such as (1)-(4) provide neither conclusive nor defeasible support for $p$ : not conclusive, since an argument with (1)-(4) as premises and $p$ as a conclusion is not a valid deductive argument, and not defeasible, since an argument with (1)-(4) as premises and $p$ as a conclusion is not a strong inductive argument, given that there are probably serious objections to $p$ that remain unconceived. ${ }^{6}$

To this some might object that disarming an objection $O$ to theory $T$ does lend some defeasible support to $T$. That is, showing that $O$ is not a serious objection to $T$ makes $T$ more likely to be true than $T$ would be if $O$ were a serious objection against $T$. Recall, however, that, given the PUO and the New Induction on the History of Philosophy, there is always another objection $\mathrm{O}_{2}$ to $T$, even if no one has conceived of $\mathrm{O}_{2}$ as an objection against $T$. Given that there is always another objection $O_{\mathrm{n}}$ to $T$, disarming objections to $T$ does not make $T$ more likely to be

\footnotetext{
${ }^{6}$ As a perceptive referee pointed out, the final conclusion of the New Induction on the History of Philosophy, i.e., (NIP3), has not played a role in my argument for the "defense $\neq$ support" thesis so far. I do make use of this conclusion in what follows. Recall that, for the purposes of this paper, anti-realism amounts to agnosticism about theoretical knowledge. See footnote 2 above.
} 
true. To see why, suppose that one is randomly drawing balls from an urn that contains one red ball and 100 blue balls. The odds of drawing a red ball are thus 1 to 100 . That is, $\operatorname{Pr}(\mathrm{R})=1 / 100$. Now, suppose we draw one blue ball from the urn and replace it with another. Has the probability of drawing a red ball changed? No; it remains $\operatorname{Pr}(\mathrm{R})=1 / 100$. In the case of sampling with replacement, the probability of drawing a red ball stays the same in each drawing, for there are always 100 blue balls and only one red ball in the urn. Similarly, even if one objection to $T$ is disarmed, the PUO and the New Induction on the History of Philosophy provide strong reasons to believe that there is always another objection to $T$ that no one has conceived of yet. That is, suppose that there are ten conceived objections against $T$. Now, suppose that one objection against $T$ is disarmed. Has the probability that $T$ is true changed? No; since the PUO and the New Induction on the History of Philosophy tell us that there are probably more objections against $T$ that we haven't even conceived of yet. If there is always another, unconceived objection to $T$, then the probability that $T$ is true does not change when objections to $T$ are disarmed, just as in the case of sampling with replacement, the odds of drawing a red ball do not change from one drawing to another. ${ }^{7}$

Now, to argumentation theorists, the point that defense is not the same as support may seem obvious. For argumentation theorists usually distinguish between argument, conceived as a set of statements in premise-conclusion form, and argumentation, conceived as an interpersonal exchange of points and counter-points. All I have shown, an argumentation theorist might think, is that disarming objections to $p$ does not in itself amount to conclusive or defeasible support for $p$. But that is a rather obvious and unproblematic point, since argumentation is more than just argument. For example, according to the pragma-dialectical approach, "argumentation [is] a complex speech act, the purpose of which is to contribute to the resolution of a difference of opinion, or dispute" (van Eemeren and Grootendorst 1992, p. 10). Likewise, according to the hyper-dialectical approach, "an argument is a defense of its conclusion from actual or potential objections" (Finocchiaro 1980, p. 419).

However, I think that the PUO and the New Induction on the History of Philosophy present these theoretical approaches to argumentation with the following problem. If a pragmadialectical (or hyper-dialectical) approach to argumentation includes anticipating and responding to objections, then a proponent of this approach has to say whether proper argumentation requires that arguers anticipate and respond only to conceived objections or to unconceived objections as well. On the one hand, drawing the line at conceived objections and claiming that proper argumentation requires that arguers anticipate and respond only to conceived objections seems rather unprincipled. Why not unconceived objections as well? On the other hand, claiming that proper argumentation requires that arguers anticipate and respond to unconceived objections seems to make argumentation hopelessly open-ended. That is to say, if argumentation is a means to resolving differences of opinion, then argumentation can never actually perform this function because there are probably unconceived objections that the parties to the exchange have failed to conceive of, which means that the parties to the exchange have good reasons to suspend judgment about the other party's position.

\footnotetext{
${ }^{7}$ Also note that my thesis is that disarming objections against a claim does not lend support (either conclusive or defeasible) to that claim. In other words, defense $\neq$ support. So to object to my thesis by claiming that disarming an objection $O$ to theory $T$ does lend some defeasible support to $T$ is to assert precisely what I deny.
} 
One might think that proponents of the pragma-dialectical approach can draw the line at conceived objections in a principled way. For, on this approach, the aim of argumentation is the resolution of differences of opinion and resolution is understood as resolution-at-a-time. That is to say, if and when new objections arise, critical discussion can always be re-opened. In that case, however, discussants have strong reasons to keep the critical discussion open at any given time, since each discussant has strong reasons (namely, the PUO and the New Induction on the History of Philosophy) to believe that the other discussant has failed to conceive of serious objections, and thus to suspend judgment about the other discussant's position.

Johnson's (2000) dialectical approach faces a similar problem. According to Johnson (2000, p. 165), an argument consists of an illative core and a dialectical tier. The illative core consists of a claim and reasons provided in support of that claim, whereas the dialectical tier consists of responses to objections. An argument, for Johnson, must have both an illative core and a dialectical tier to properly count as an argument. As Johnson (2000, p. 168) writes:

An argument is a type of discourse or text - the distillate of the practice of argumentation - in which the arguer seeks to persuade the Other(s) of the truth of a thesis by producing the reasons that support it. In addition to this illative core, an argument possesses a dialectical tier in which the arguer discharges his dialectical obligations.

Accordingly, Johnson's dialectical approach puts a dialectical obligation on arguers to anticipate and respond to objections. In that case, a proponent of the dialectical approach has to say whether arguers are dialectically obliged to anticipate and respond only to conceived objections or to unconceived objections as well. On the one hand, claiming that arguers are dialectically obliged to anticipate and respond only to conceived objections seems rather unprincipled. Why not unconceived objections as well? On the other hand, claiming that arguers are dialectically obliged to anticipate and respond to unconceived objections as well seems to make argumentation hopelessly open-ended. That is to say, if the aim of argumentation is to persuade, then argumentation can never actually achieve this aim because each party to the exchange has strong reasons (namely, the PUO and the New Induction on the History of Philosophy) to believe that there are probably unconceived objections that the other party to the exchange has failed to conceive of, and thus to suspend judgment about the other party's position.

In his discussion of what he calls "the specification problem," i.e., the extent of the objections that an arguer has a dialectical obligation to anticipate and respond to, Johnson (2000, p. 328) considers the following options: (a) "all possible and actual objections," (b) "objections that she or he knows how to address," and (c) "those objections that the audience will want to see addressed." Johnson considers each option but he thinks that the specification problem is one of the open questions that his dialectical approach has to address. If the aforementioned considerations are correct, however, then the specification problem is even worse than what Johnson had thought. For the PUO shows that there are probably objections that arguers haven't even conceived of, which means that each arguer has good reasons to suspend judgment about the other arguer's position.

One might think that proponents of the dialectical approach to argumentation can draw the line at conceived objections in a principled way. They can do so by appealing to the "Ought Implies Can" principle and argue that arguers are not dialectically obliged to do something they 
cannot do, namely, respond to unconceived objections. Even if 'ought' does imply 'can', 8 however, proponents of the dialectical approach would still face the following problem. If each party to an argumentative exchange seeks to persuade the other, and doing so requires each party to discharge his or her dialectical obligations, then, in light of the PUO and the New Induction on the History of Philosophy, this can never be attained. Why? Because each party to the exchange has strong reasons (namely, the PUO and the New Induction on the History of Philosophy) to believe that the other party has failed to conceive of serious objections, and thus to remain agnostic about the other party's position. Similarly, on a pragma-dialectical approach to argumentation, if the aim of argumentation is the resolution of disputes, and doing so requires each party to anticipate and respond to objections, then, in light of the PUO and the New Induction on the History of Philosophy, this can never be attained. Why? Because each party to the exchange has strong reasons (namely, the PUO and the New Induction on the History of Philosophy) to believe that the other party has failed to conceive of serious objections, and thus to remain agnostic about the other party's position.

\section{Conclusion}

In this paper, I have argued that, just as the Problem of Unconceived Alternatives (PUA) provides a basis for a New Induction on the History of Science to the effect that a realist view of science is unwarranted, the Problem of Unconceived Objections (PUO) provides a basis for a New Induction on the History of Philosophy to the effect that a realist view of philosophy is unwarranted. I have raised this problem not only for skepticism's sake but also for the sake of making a point about philosophical argumentation, namely, that anticipating objections to one's claim is not the same as supporting that claim. In other words, defending $p$ from objections does not amount to support - whether conclusive (as in deductive arguments) or defeasible (as in inductive arguments) - for $p$. This, in turn, presents dialectical approaches to argumentation with the following problem: does proper argumentation require that arguers anticipate and respond to unconceived objections? If not, why not? If so, then the supposed aims of argumentation, namely, persuasion and resolution, cannot be attained, since each party to the exchange has strong reasons (namely, the PUO and the New Induction on the History of Philosophy) to believe that the other party has failed to conceive of serious objections, and thus to remain agnostic about the other party's position.

\section{Acknowledgments}

I am very grateful to two reviewers of Argumentation for invaluable comments on earlier drafts.

\section{References}

Achinstein, P. (2001). The Book of Evidence. New York: Oxford University Press.

\footnotetext{
${ }^{8}$ On whether 'ought' implies 'can', see Mizrahi (2009) and (2012c).
} 
Alston, W. P. (1986). Perceiving God. The Journal of Philosophy, 83, 655-665.

Ayer, A. J. (1936). Language, Truth, and Logic. London: Gollancz.

Ayer, A. J. (1946). Language, Truth, and Logic. $2^{\text {nd }}$ Ed. London: Gollancz.

Baergen, R. (1995). Contemporary Epistemology. Fort Worth, TX: Harcourt Brace College Publishers.

Brock, S. (1993). Modal Fictionalism: A Response to Rosen. Mind, 102, 147-150.

Chakravartty, A. (2013). Scientific Realism. In E. N. Zalta, The Stanford Encyclopedia of Philosophy (Summer 2013 Edition).

http://plato.stanford.edu/archives/sum2013/entries/scientific-realism/.

Church, A. (1949). Review of Language, Truth, and Logic. Journal of Symbolic Logic, 14, 5253.

Dogan, A. (2005). Confirmation of Scientific Hypotheses as Relations. Journal of General Philosophy of Science, 36, 243-259.

Eemeren, F. H. van and Grootendorst, R. (1992). Argumentation, Communication, and Fallacies: A Pragma-Dialectical Perspective. Hillsdale, NJ: Lawrence Erlbaum Associates.

Erwin, E. and Siegel, H. (1989). Is Confirmation Differential? British Journal for the Philosophy of Science, 40, 105-119.

Filmer, R. (1680/1991). Patriarcha and Other Writings. J. P. Sommerville (Ed.). Cambridge: Cambridge University Press.

Gauthier, D. (1986). Morals by Agreement. New York: Oxford University Press.

Gettier, E. (1963). Is Justified True Belief Knowledge? Analysis, 23, 121-123.

Grünbaum, A. (1976). Is the Method of Bold Conjectures and Attempted Refutations Justifiably the Method of Science? British Journal for the Philosophy of Science, 27, 105-136.

Hale, B. (1995). Modal Fictionalism: A Simple Dilemma. Analysis, 55, 63-67.

Iranzo, V. (2007). Abduction and Inference to the Best Explanation. Theoria, 60, 339-346.

Johnson, R. H. (2000). Manifest Rationality: A Pragmatic Theory of Argument. Mahwah, N.J.: Lawrence Earlbaum.

Kripke, S. (1980). Naming and Necessity. Cambridge: Harvard University Press.

Kuhn, T. (1962). The Structure of Scientific Revolutions. Chicago: University of Chicago Press.

Laudan, L. (1981). A Confutation of Convergent Realism. Philosophy of Science, 48, 19-49.

Locke, J. (1689/1988). Two Treatises of Government. P. Laslett (Ed.). Cambridge: Cambridge University Press. 
Magnus, P. D. (2006). What's New about the New Induction? Synthese, 148, 295-301.

Magnus, P. D. (2010). Inductions, Red Herrings, and the Best Explanation for the Mixed Record of Science. British Journal for the Philosophy of Science, 61, 803-819.

Miller, D. (1974). Popper's Qualitative Theory of Verisimilitude. The British Journal for the Philosophy of Science, 25, 166-177.

Mizrahi, M. (2009). 'Ought’ Does Not Imply 'Can'. Philosophical Frontiers, 4, 19-35.

Mizrahi, M. (2012a). Why the Ultimate Argument for Scientific Realism Ultimately Fails. Studies in History and Philosophy of Science Part A, 43, 132-138.

Mizrahi, M. (2012b). The Pessimistic Induction: A Bad Argument Gone Too Far. Synthese. DOI $10.1007 / \mathrm{s} 11229-012-0138-3$.

Mizrahi, M. (2012c). Does 'Ought' Imply 'Can' from an Epistemic Point of View? Philosophia, 40, 829-840.

Muller, F. A. (2008). In Defence of Constructive Empiricism: Maxwell's Master Argument and Aberrant Theories. Journal for General Philosophy of Science, 39, 131-156.

Pollock, J. (1986). Contemporary Theories of Knowledge. Totowa: Rowman and Littlefield.

Popper, K. (1963). Conjectures and Refutations: The Growth of Scientific Knowledge. Routledge, London.

Psillos, S. (1999). Scientific Realism: How Science Tracks Truth. London: Routledge.

Psillos, S. (2002). Simply the Best: A Case for Abduction. In A. C. Kakas and F. Sadri (Eds.), Computational Logic: Logic Programming and Beyond Part II (pp. 605-626). Berlin: SpringerVerlag.

Psillos, S. (2006). Thinking about the Ultimate Argument for Realism. In C. Cheyne and J. Worrall (Eds.), Rationality \& Reality: Essays in Honour of Alan Musgrave (pp. 133-156). Dordrecht: Springer.

Psillos, S. (2007). The Fine Structure of Inference to the Best Explanation. Philosophy and Phenomenological Research, LXXIV(2), 441-448.

Rosen, G. (1990). Modal Fictionalism. Mind, 99, 327-354.

Russell, B. (1905). On Denoting. Mind, 14, 479-493.

Russell, B. (1919). Introduction to Mathematical Philosophy. London: George Allen and Unwin.

Shope, R. K. (1983). The Analysis of Knowing: A Decade of Research. Princeton: Princeton University Press.

Silvers, A. and Francis, L. P. (2005). Justice through Trust: Disability and the Outlier Problem in Social Contract Theory. Ethics, 116, 40-76. 
Stanford, P. K. (2006). Exceeding Our Grasp: Science, History, and the Problem of Unconceived Alternatives. Oxford University Press.

Tichý, P. (1974). On Popper's Definitions of Verisimilitude. The British Journal for the Philosophy of Science, 25, 155-160.

Turri, J. (2011). Manifest Failure: The Gettier Problem Solved. Philosophers' Imprint, 11, 1-11.

Van Fraassen, B. C. (1980). The Scientific Image. New York: Oxford University Press.

Van Fraassen, B. C. (1998). The Agnostic Subtly Probabilified. Analysis, 58, 212-220. 